\title{
Antisaccade models
}

$\underline{\text { Affliation details }}$

Vassilis Cutsuridis $^{*}$

School of Computer Science

University of Lincoln

Lincoln, LN6 7TS

U.K.

Email: vcutsuridis@ @incoln.ac.uk, vcutsuridis@ gmail.com

Tel: +44 (0) 1522835107

*Corresponding author 


\section{Definition}

The antisaccade task in its most typical form (the visually guided antisaccade; Fig. 1) is a reaction time task in which subjects are instructed to perform an immediate eye movement in the opposite direction to a peripheral stimulus, which is presented in their right or left visual field, while they are fixating on a central stimulus (Hallett, 1978). Variations of the typical antisaccade (gap antisaccade and overlap antisaccade;

Fig 1) in the horizontal or vertical plane were designed over the years to investigate the effect of the fixation stimulus on the decision to move (Goldring and Fischer, 1997; Forbes and Klein, 1996; Fischer et al., 1997).

\section{Detailed Description}

\section{Basic antisaccade behaviour}

The antisaccade task was first developed to dissociate the stimulus location from the goal of the saccade. During a single trial of the antisaccade task two processes take place: (1) suppression of an erroneous prosaccade towards the peripheral stimulus, and (2) generation of a volitional saccade to a position in the opposite direction (antisaccade) (Munoz and Everling, 2004). In a single trial, a participant may express any of the following three oculomotor behaviours: (1) the subject makes an antisaccade (an eye movement in the opposite direction of the peripheral stimulus), or (2) the subject makes an erroneous prosaccade (an eye movement in the direction of the peripheral stimulus), or (3) the subject makes an erroneous prosaccade followed by a corrected antisaccade. An error is an eye movement toward the peripheral stimulus instead of the opposite direction. Antisaccade performance involves different metrics such as the mean and standard deviation of the saccade reaction time (SRT) of 
each eye movement as well as the error rate (Ettinger et al., 2003). Healthy participants typically fail to suppress erroneous prosaccades toward the target on about $20-25 \%$ of trials, before correctly saccading toward a location in the opposite direction (Fischer and Weber, 1992; Everling and Fischer, 1998; Smyrnis et al., 2002; Ettinger et al., 2003; Tatler and Hutton, 2007). Unimodal skewed to the right distributions of antisaccades, erroneous prosaccades and corrected antisaccades are observed. The mean and standard deviation of the antisaccade reaction time from a large cohort of 2006 healthy subjects is reported to be $270 \mathrm{~ms}$ and $56 \mathrm{~ms}$, respectively (Evdokimidis et al., 2002). In the same group, the mean and standard deviation of the erroneous prosaccade reaction time is $208 \mathrm{~ms}$ and $46 \mathrm{~ms}$, respectively, whereas the mean and standard deviation of the corrected antisaccade reaction time is $146 \mathrm{~ms}$ and $85 \mathrm{~ms}$, respectively (Evdokimidis et al., 2002).

\section{Antisaccade oculomotor circuit}

The antisaccade oculomotor circuit consists of several cortical and subcortical areas including the frontal eye fields (FEF), supplementary eye fields (SEF), dorsolateral prefrontal cortex (DLPFC), anterior cingulate cortex (ACC), lateral intraparietal area (LIP) (parietal eye field (PEF) in the human), basal ganglia, thalamus, superior colliculus (SC), brainstem reticular formation, and cerebellum (Munoz and Everling, 2004). Visual information is processed via the retino-geniculo-cortical pathway to primary visual cortex and from there to LIP/PEF and via the retinotectal pathway to the superficial layers of the SC (SCs). LIP is an area in the parietal cortex coding for space. LIP/PEF then projects to both the intermediate layers of the SC (SCi) and frontal cortical oculomotor areas including FEF, SEF, ACC and DLPFC. FEF is critical for voluntary saccade execution. SEF is implicated in internally guided 
decision-making and sequencing of saccades. AAC plays a role in conflict resolution and error monitoring. DLPFC is critical in executive function, spatial working memory, and suppressing automated or reflexive responses. These frontal oculomotor areas project to $\mathrm{SCi}$, an area important for decision making, which then projects to the reticular formation of the brainstem to provide the necessary input to guide saccades.

Another pathway to $\mathrm{SCi}$ from the frontal oculomotor areas is through the basal ganglia structures via the direct, indirect and hyperdirect pathways (Munoz and Everling, 2004). Via the direct pathway frontal areas project to the caudate nucleus (CD), which in turn inhibits the substantia nigra pars reticulata ( $\mathrm{SNr}$ ). $\mathrm{SNr}$ disinhibits the SCi and motor nuclei of thalamus, which project back to frontal cortex. Via the indirect pathway $\mathrm{CD}$ projects to the external segment of the globus pallidus (GPe), which in turn project to the subthalamic nucleus (STN). STN sends excitatory projections to $\mathrm{SNr}$ and $\mathrm{GPe}$, which projects via GABAergic connections back to $\mathrm{SNr}$. Via the hyperdirect pathway cortical regions excite STN, which in turn excite SNr. These complex sets of excitatory and inhibitory projections within the basal ganglia provide a rich set of control mechanisms to help guide voluntary behaviour (Coe and Munoz, 2017)

\section{Primate neurophysiology overview}

A number of brain areas in monkeys are involved in the antisaccade task, including the DLPFC (Funahashi et al., 1993), the ACC (Philips et al., 2010), the LIP (Gottlieb and Goldberg, 1999), the SEF (Schlag-Rey et al., 1997; Amador et al., 2004), the FEF (Everling and Munoz, 2000) and the SC (Everling et al., 1999). Understanding how neurons in these brain areas participate in the suppression of automatic responses and the generation of antisaccades is crucial for explaining the antisaccade behaviour. 
Single neuron recordings in FEF and SC have revealed the existence of two distinct and reciprocally activated populations of neurons: the fixation cells and the saccade cells. Fixation cells are tonically active during visual fixation and their activity ceases when a saccade is executed. On the other hand, saccade cells are silent during fixation, but discharge when the animal is making a saccade. In SC two distinct types of saccade neurons have been recorded: build-up and burst cells (Munoz and Wurtz, 1995a, 1995b). A network of inhibitory interneurons is thought to control the reciprocal activation of fixation and saccade neurons (Munoz and Istvan, 1998). During fixation in the gap condition (gap prosaccade versus gap antisaccade), fixation activity is greater in the antisaccade trials than in the prosaccade trials in both FEF and SC. This pattern of enhanced fixation activity explains the so-called 'anti-effect' (Munoz and Everling, 2004): longer reaction times on antisaccade trials than on prosaccade trials. A few ms into the gap period, there is a drop in activity of fixation neurons and a slow build-up of low-frequency activity of a subset of saccade neurons in both SC (Everling et al., 1999) and FEF (Everling and Munoz, 2000). The appearance of the visual stimulus in the right visual field leads to phasic activation of visually responsive saccade neurons in FEF and SC on the contralateral (left) side of the brain, and to phasic inhibition of saccade neurons on the ipsilateral (right) side of the brain. On the prosaccade trials, saccade neurons on the left side discharge a saccadic burst for the rightward prosaccade immediately after the visual phasic response. On antisaccade trials, the saccade neurons in the left FEF and SC are inhibited compared to saccade neurons in the right FEF and SC, which are active to drive the leftward antisaccade.

Recordings from neurons in PFC in rhesus monkeys trained to perform a delayed antisaccade task (Funahashi et al., 1993) revealed that most PFC neurons code the location of the visual stimulus in working memory, and this memory can be 
engaged to suppress and prescribe a response. Response-coding neurons in smaller percentages were also found, some of which increased their firing rate for the direction of the saccade (e.g rightward saccade) irrespective of the stimulus location, and others coding for both stimulus location and saccade direction. Similarly, recordings in LIP (Gottlieb and Goldberg, 1999) also revealed the majority of LIP neurons reliably coding for the encoded cue location, with only a very small minority encoding for the direction of the upcoming saccade.

Electrical microstimulation in dorsal AAC in monkeys performing alternating blocks of prosaccade and antisaccade trials (Philips et al., 2010) suggested a direct role of AAC in antisaccade performance. On antisaccade trials, microstimulation decreased SRTs for both ipsi- and contralateral directed antisaccades. On the other hand on prosaccade trials, SRTs were increased for saccades contralateral to and decreased for saccades ipsilateral to the stimulated hemisphere.

Finally, recordings from SEF in monkeys (Amador et al., 2004; Schlag-Rey et al., 1997) showed that the vast majority of SEF movement neurons fired significantly more before antisaccades than before prosaccades. The level of their firing was predictive of the correct performance on antisaccades on individual trials.

\section{Antisaccade performance across lifespan}

Antisaccade performance varies systematically with age - (Munoz et al., 1998; Klein and Foerster, 2001; Pletch et al., 2011). Young children (5-8 years old) have slow SRTs, large intra-subject SRT variance, and the largest error rate in the anti-saccade task. Young adults (20-30 years of age) typically have the fastest SRTs, the lowest intra-subject variance in SRT and the fewest direction errors. Elderly subjects (60-85 years of age) have slower SRTs than other subject groups. These results demonstrate 
very strong positive correlation of age and subject antisaccade performance, which may reflect different stages of normal development and degeneration in the nervous system. The dramatic improvement in antisaccade performance observed from the ages of 5 to 15 years is attributed to delayed maturation of the frontal lobes.

\section{Antisaccade performance in disorders}

Antisaccade performance has been investigated in many neurological and psychiatric disorders including attention deficit hyperactivity disorder [60,61], fetal alcohol spectrum disorders [62, 63], Huntington disease [64], Parkinson's disease [65-67, 8182], Alzheimer's disease [68, 84], mild cognitive impairment [68, 83], amyotrophic lateral sclerosis [69], bipolar disease [70], schizophrenia [71-73], obsessivecompulsive disorder [74,75], Tourette syndrome [75], multiple sclerosis [76], depression [77,78], epilepsy [Lunn et al.], ventrolateral prefrontal damage [Hogdson et al., 2007] and frontotemporal dementia [79,80].

In particular, patients with frontal lobe lesions (Guitton et al., 1985; PierrotDeseilligny et al., 2002) and patients suffering from schizophrenia (Fukushima et al., 1988) make more antisaccade errors and their antisaccade latencies are more variable within and across subjects (Fukushima et al., 1988; Hutton et al., 1998; Karoumi et al., 1998; Brownstein et al., 2003). An increase in correct antisaccade mean latency in schizophrenia patients was recently reported (Damilou et al., 2016). Impaired antisaccade task performance has also been reported in patients with recent onset schizophrenia and first-episode schizophrenia (deWilde et al., 2008; Ettinger et al., 2004; Grootens et al., 2008; Hutton et al., 2002; Hutton et al., 1998; Kirenskaya et al., 2013), chronic schizophrenia (Boudet et al., 2005; Curtis et al., 2001; Fukushima et al., 1988; Behrwind et al., 2011) and remitted schizophrenia (Curtis et al., 2001). 
Aberrant antisaccade performance has also been reported by first degree unaffected biological relatives of schizophrenia patients (Kang et al., 2011; Radant et al., 2010; Zanelli et al., 2009). The antisaccade performance deficit in schizophrenia patients is reported to be due to: (1) a deficit in top-down inhibition control of the erroneous response (Everling and Fischer, 1998; Broerse et al., 2001; Brownstein et al., 2003; Curtis et al. 2001), (2) a deficit in response generation of the antisaccade (Everling and Fischer, 1998; Broerse et al., 2001; Brownstein et al., 2003; Curtis et al. 2001), or (3) an emergent property of competing noisy decision accumulating processes (the erroneous prosaccade and the antisaccade) (Cutsuridis et al., 2014; Cutsuridis, 2010).

Various psychopharmacological manipulations including administration of lorazepam (Green \& King, 1998; Green, King, \& Trimble, 2000), risperidone (Burke \& Reveley, 2002; Hutton, 2002), nicotine (Petrovsky et al., 2012; Rycroft et al., 2007; Depatie et al., 2002; Larrison-Faucher et al., 2004), amphetamine (Dursun et al, 1999), and modafinil (Rycroft et al., 2007) led to changes in the antisaccade performance of cohorts of patients. Risperidone has been observed to improve error rates in some schizophrenia patients (Burke \& Reveley, 2002; Hutton, 2002). Nicotine administration in schizophrenia patients improves their antisaccade performance (Petrovsky et al., 2013; Depatie et al., 2002; Larrison-Faucher et al., 2004).

Antisaccade performance, on the other hand, of obsessive compulsive (OCD) patients has been variable and contradictory. Initial studies reported increased error rates in OCD patients compared to healthy controls, but no difference in their latencies of antisaccades (Tien et al., 1992). Other studies reported higher antisaccade latencies in OCD patients compared to healthy controls, while their error rate did not differ significantly (Maruff et al., 1999; van der Wee et al., 2006). Another study observed no differences in error rates and latencies of antisaccades between OCD patients and healthy subjects (Kloft et al., 2011). An increase in error rates and in 
latency of corrected antisaccades was recently reported (Damilou et al., 2016). It is speculated that the OCD antisaccade performance is due to a deficit in erroneous response inhibition control in the oculomotor circuit (Chamberlain et al., 2005; Everling and Fischer, 1998; Broerse et al., 2001; Brownstein et al., 2003; Curtis et al. 2001)

\section{Types of theoretical models of antisaccade performance}

Theoretical models of antisaccade performance fall under two categories:

- Accumulator models: In these models the process of decision making often involves a linear gradual accumulation of information concerning the various potential responses starting at some baseline level $S_{0}$, which represents the prior expectation, at a constant rate $\mathrm{r}$ until it reaches a threshold $\mathrm{S}_{\mathrm{T}}$, which represents the confidence level required before the commitment to a particular course of action. Once the decision signal crosses $\mathrm{S}_{\mathrm{T}}$, then a response towards the target is initiated. Response time (RT) is measured as the time from the onset of the decision process till when the decision signal crosses $\mathbf{S}_{\mathrm{T}}$. Often the rate of accumulation is assumed to vary randomly from trial to trial, with a mean $\mu$ and variance $\sigma^{2}$ (Reddi and Carpenter, 2000). Changes in the baseline level of activity, the rate of accumulation or the threshold often result in changes in response latency. Prior expectation and level of activation of intention influence the baseline levels of activation.

- Neural accumulator models: In these models the accumulation process is represented by the firing rate of usually a population of neurons. Changes in the rate (slow or fast) of neural firing are usually non-linear, often competing and reflect the changes in the rate of accumulation in the linear accumulator 
models. Once the neural firing rate crosses a threshold, then a decision is made.

Below I will review models of various degrees of antisaccade performance from both categories.

\section{Accumulator models}

A notable modelling attempt of the antisaccade paradigm was Noorani's and Carpenter's (2013) three-unit model (see Fig. 2A). The model consisted of three LATER units racing to threshold: an ANTI unit, a PRO unit, and a STOP unit. An important model feature was that the ANTI unit was identical ( $\mu$ and $\sigma$ ) to the PRO unit. In the model, the STOP unit prevented the PRO unit from reaching threshold, thus allowing the ANTI unit to reach a different threshold a little later. The authors hypothesized that the threshold level of the PRO unit was higher than the ANTI unit's threshold, reflecting the advice given by the experimenters to every subject to avoid errors. How often the STOP unit cancelled the PRO unit depended on its rate of accumulation $(\mu)$ and its variance $\left(\sigma^{2}\right)$. The model's performance was contrasted against the performance of five healthy subjects performing the antisaccade task. The model captured most of the response repertoire observed in the antisaccade task, namely the antisaccades and the erroneous prosaccades, their corresponding latency distributions and the error response rate. Despite the model's successes, the model had several shortcomings. The model failed to produce "the erroneous prosaccade followed by the corrected antisaccade" behaviour. Moreover, the model postulated the existence of a third inhibitory signal (the STOP signal), which occasionally stopped the erroneous prosaccade response and indirectly allowed just the antisaccade 
response to be expressed. Recent experimental evidence has challenged the existence of such a third signal (Everling and Johnston, 2013).

To address some of these shortcomings Noorani and Carpenter (2014) extended their previous model (Noorani and Carpenter, 2013) by including a RESTART mechanism (see Fig. 2B). In this case when the PRO unit reached the threshold first, it restarted the ANTI unit allowing it to reach the threshold and generate the antisaccade response. Their new model successfully reproduced the "erroneous prosaccade followed by the corrected antisaccade" behaviour, but failed now to reproduce the just erroneous prosaccades. This shortcoming was inherent in their model. The authors postulated that if the STOP signal did not prevent the erroneous prosaccade response, then the PRO unit will always restart the ANTI unit (Noorani and Carpenter, 2014). This meant the erroneous prosaccades followed by corrected antisaccades will always be produced. If the STOP unit did prevent the PRO unit, then the ANTI unit would not re-start (the corrected antisaccade will not be produced), and an antisaccade response would be generated (Noorani and Carpenter, 2014). In either scenario, just an erroneous prosaccade response cannot be generated. The authors claimed in their studies participants never made any just erroneous prosaccades (private communication of the author with Roger Carpenter). However, psychophysical studies of a large group of 2006 participants performing the antisaccade task (Evdokimidis et al., 2002) reported that subjects do make the just erroneous prosaccades, but their response frequency is low. Another limitation of their new model was their consideration that the simulated latency of the corrected antisaccade is the result of the linear sum of latencies of the erroneous prosaccade and the antisaccade minus the latency of the STOP activity. This shortcoming was inherent in the model, because its units are considered linear encoders of the input information. 
The three-unit antisaccade model was recently applied to a large sample of Huntington's disease (HD) patients against healthy controls in an effort to quantitatively predict HD before symptom onset (Wiecki et al., 2016). Experimental RT distributions and error rates of pre-manifest individuals carrying the HD mutation (pre-HD), early symptomatic and healthy controls performing the antisaccade conflict task were fit using the three-unit antisaccade model. Further machine learning analysis based on fitted model parameters revealed a key executive control parameter was predictive of HD prior to symptom onset, whereas response inhibition processes are impaired only after the motor symptoms are observed.

Extensions of the three-unit antisaccade model were very recently introduced by Aponte and colleagues (2017) in the form of three probabilistic models, PROSA, SERIA and SERIA lr $_{\text {. SERIA }}$ (see Fig. 3) predicted that two decision processes (one early race between a prepotent response towards a target and an endogenously generated signal to cancel this action, and a secondary late race between two units encoding two cue-action mappings) are necessary to properly model the antisaccade task. The two decision processes in SERIA 1 were considered to be the sources of early errors, fast erroneous prosaccades in antisaccade trials, and late errors, late actions incongruent with the cue presented. Bayesian model comparison showed that the SERIA ${ }_{\text {lr }}$ model explains the data better than other competing models that did not incorporate a late decision process. Early decision processes were predicted to be insensitive to cue presented in every trial. Changes in reaction time and error rate due to probability of trial type were best explained by faster or slower inhibition in the model. 


\section{Neural accumulator models}

\section{Rate based models}

The first ever attempt to simulate the antisaccade task and uncover its neural mechanisms was made by Cutsuridis and colleagues (2007a) when they introduced a neural non-linear accumulator model with competition via lateral inhibition between its components. The model was a 1D layer neuronal arrangement of the intermediate layer of SC with three different types of cells, namely the fixation, buildup and burst neurons (Trappenberg et al., 2001) (see Fig. 4). In the model, the fixation cells were activated by the fixation stimulus, and the buildup and burst cells by two inputs, a reactive input that represented the erroneous prosaccade motor plan and originated from the lateral intraparietal (LIP) area (Gottlieb and Goldberg, 1999) and a planned input which represented the antisaccade motor plan and originated from FEF (Everling and Munoz, 2000). The inputs were linear ramping processes till a maximum value after which they were either abruptly brought or smoothly decayed to zero. The slopes values of these linearly ramping processes took values from Gaussian distributions with different means and standard deviations for each input. Both inputs were integrated by spatially distant buildup and burst cells, which competed one another via lateral inhibition (Munoz and Istvan, 1998). Each simulation trial started with the model fixation cells firing maximally for as much time as the subjects were fixating to the central stimulus and buildup and burst cells being silent. As soon as the peripheral stimulus appeared and the subjects had to make an antisaccade, then the model fixation activity started to decay to zero and the builup cell activity stated to rise. In the model the buildup cells had the role of accumulator cells that integrated evidence till some user pre-set threshold. Once the threshold was 
crossed, then the cue was given to the model burst cells to fire maximally, but for a short period of time (phasic activation). In the model the burst activity represented the final motor command given to the eyes to move. Occasionally in some simulated trials both erroneous prosaccade and antisaccade buildup cells crossed the threshold, which then cued their corresponding burst cells to fire. Behaviourally that meant that the virtual subject made an erroneous prosaccade first and corrected with an antisaccade. The model was able to produce all three oculomotor behaviours of the antisaccade task, namely the erroneous prosaccade, the antisaccade and the corrected antisaccade. The model was also able to simulate accurately the antisaccade performance (latency distributions of the erroneous prosaccades and antisaccades as well as the error rates) of 10 virtual groups of participants with only 5 free parameters. The model predicted that competition via lateral inhibition and $\underline{\text { not }}$ a third inhibitory signal accounts for the antisaccade performance of a large cohort of healthy participants. Despite its successes the model suffered from shortcomings. The simulated discharged rates of the fixation and buildup cells were unrealistically high (roughly 600Hz) (Munoz and Wurz, 1993, 1995a, 1995b). For lower discharged rates the model can still accurately simulate the behavioural and neurophysiological properties of the antisaccade task, but for different parameter values (unpublished observations). Furthermore, the model failed to uncover the ionic and synaptic mechanisms that may produce the range of values of input slopes needed to produce the latency distributions of the erroneous prosaccades and antisaccades.

Recently, Cutsuridis extended his neural non-linear accumulator with competition model of antisaccade performance (Cutsuridis et al., 2007a) into the disorder domains of schizophrenia and obsessive-compulsive disorder (OCD) (Cutsuridis et al., 2014; Cutsuridis, 2017b). In the new model (see Fig. 5) variations in the integration constants of buildup cell activities in the model SC and not in the 
slopes of the ramping phases of the cortical inputs produced the error rates and latency distributions of the erroneous prosaccades, antisaccades and corrected antisaccades of healthy controls (Ettinger et al., 2003), schizophrenia and OCD (Damilou et al., 2016) suffering subjects. The model showed that the poor antisaccade performance in schizophrenia is due to a more noisy accumulation of information, but the schizophrenia patients are as confident (threshold level is unchanged) as their healthy counterparts (Cutsuridis et al., 2014). In contrast, in OCD, the accumulation of information is also noisy, but the OCD subjects are less confident (threshold level is changed) than the healthy participants (Cutsuridis, 2017b). In both disorders the model predicted the antisaccade performance is not due to a deficit in the top-down inhibitory control of the erroneous response as many speculated, but instead it is due to a local inhibitory mechanism in the form of a competitive race to a threshold between the buildup cell representations of the erroneous prosaccade and antisaccade in SC. In favour of this competitive race to a threshold between competing prosaccade and antisaccade signals is the Massen (2004) study, which selectively manipulated the exogenous and endogenous processes in the antisaccade task (e.g. slowing down or speeding up one of these or both processes) and observed the effects of this manipulation on error rate. Massen (2004) observed that if a manipulation slowed the generation of antisaccades, while having no effect on prosaccade generation, then the error rate was increased. If, however, manipulation influenced both pro- and antisaccade generation to the same degree, then the error rate remained unchanged. Massen (2004) argued that antisaccade performance is explained in terms of a competition between two parallel programmes for saccade execution: if the volitional antisaccade is programmed fast enough (e.g., reaches some threshold for activation), then it will win the competition, and the reflexive prosaccade will be cancelled. Alternatively, if the prosaccade is programmed fast enough or the computation for the 
antisaccade is too slow) an erroneous prosaccade will be made first followed by the correct antisaccade. This account in line with Cutsuridis and colleagues' (2007a, 2014, 2017b) computational studies favoured the concept of an active inhibitory mechanism in the form of competition between competing decision signals as being critical to antisaccade performance.

\section{Spiking neuron models}

To uncover the ionic and synaptic mechanisms that produced the range of values of accumulation rates needed to produce the latency distributions of the erroneous prosaccades and antisaccades in Cutsuridis and colleagues' (2007a) model, the same group (Cutsuridis et al., 2007b) introduced a multi modular neural network model consisting of two cortical modules (FEF and LIP) that drove the SC module to decide the winning motor command to move the eyes (Fig 4). Each cortical module was a network of Hodgkin-Huxley type excitatory and inhibitory neurons connected together. The SC module was the same as in Cutsuridis and colleagues' (2007a) study. No connectivity was assumed between the cortical modules although it has been experimentally observed (Schall, 1997). Symmetric and asymmetric connection types were tried. Background noise and synaptic noise were also included in the cortical model neurons and in their connections to simulate homogeneous and heterogeneous neuronal firings. The population activity from each cortical network was extracted and a line was fitted to its ramping activity to estimate its slope. Variations in all model ionic and synaptic conductances were attempted to uncover which current(s) and what range of their conductance values reproduced the full range of slope values of the planned and reactive inputs to the SC model needed to reproduce the latency distributions and error rates of the virtual groups of participants 
in the Cutsuridis et al (2007a) study. The model predicted that only conductance variations of the persistent $\mathrm{Na}^{+}, \mathrm{NMDA}$ and AMPA currents could produce the necessary slope variability in the cortical decision signals to reproduce the latency distributions and response probabilities of the virtual subjects.

Recently, a two-module spiking with competition network model of antisaccade performance was advanced by Lo and Wang (2016). The model consisting of sensorimotor remapping and action selection modules, the latter endowed by a "Stop" process through tonic inhibition, both under the modulation of rule-dependent control revealed the circuit mechanisms for the experimentally observed distributions of erroneous responses in the antisaccade task. In the model, fast errors resulted from failing to inhibit the quick automatic responses and therefore exhibited very short response times. Slow errors, on the other hand, were due to an incorrect decision in the remapping process and exhibited long response times comparable to those of correct antisaccade responses. 


\section{References}

Aichert DS, Derntl B, Wöstmann NM, Groß JK, Dehning S, Cerovecki A, Möller HJ, Habel U, Riedel M, Ettinger U (2013) Intact emotion-cognition interaction in schizophrenia patients and first-degree relatives: evidence from an emotional antisaccade task. Brain Cogn. 82(3): 329-36

Amador N, Schlag-Rey M, Schlag J (2004) Primate antisaccade. II. Supplementary eye field neuronal activity predicts correct performance. J Neurophysiol 91: 1672-89

Amador SC, Hood AJ, Schiess MC, Izor R, Sereno AB (2006) Dissociating cognitive deficits involved in voluntary eye movement dysfunctions in Parkinson's disease patients. Neuropsychologia 44: 1475-1482.

Antoniades CA, Demeyere N, Kennard C, Humphreys GW, Hu MT (2015) Antisaccades and executive dysfunction in early drug-naive Parkinson's disease: the discovery study. Mov. Disord. 30: 843-847.

Antoniades C, Ettinger U, Gaymard B, Gilchrist I, Kristjánsson A, Kennard C, John Leigh R, Noorani I, Pouget P, Smyrnis N, Tarnowski A, Zee DS, Carpenter RH (2013) An internationally standardised antisaccade protocol. Vision Res. 84: 1-5. doi: 10.1016/j.visres.2013.02.007

Aponte EA, Schöbi D, Stephan KE, Heinzle J (2017) The stochastic early reaction, inhibition, and late action (SERIA) model for antisaccades. PLoS Comput Biol. 13(8): e1005692. doi: 10.1371/journal.pcbi.1005692

Behrwind SD, Dafotakis M, Halfter S, Hobusch K, Berthold-Losleben M, Cieslik EC, Eickhoff SB (2011) Executive control in chronic schizophrenia: A perspective from manual stimulus-response compatibility task performance. Behav Brain Res. 223(1): 24-9

Boudet C, Bocca ML, Chabot B, Delamillieure P, Brazo P, Denise P, Dollfus S (2005) Are eye movement abnormalities indicators of genetic vulnerability to schizophrenia? European Psychiatry 30: 339-345.

Boxer AL, Garbutt S, Seeley WW, Jafari A, Heuer HW, Mirsky J, Hellmuth J, Trojanowski JQ, Huang E, DeArmond S, Neuhaus J, Miller BL (2012) Saccade abnormalities in autopsy-confirmed frontotemporal lobar degeneration and Alzheimer disease. Arch. Neurol. 69: 509-517

Broerse A, Crawford TJ, den Boer JA (2001) Parsing cognition in schizophrenia using saccadic eye movements: a selective overview. Neuropsychologia 39: 742-756

Brownstein J, Krastoshevsky O, McCollum C, Kundamal S, Matthysse S, Holzman PS, Mendell NR, Levy DL (2003) Antisaccade performance is abnormal in schizophrenia patients, but not in their biological relatives. Schizophrenia Res 63: 1325 
Burke JG, Reveley MA (2002) Improved antisaccade performance with risperidone in schizophrenia. Journal of Neurology, Neurosurgery, and Psychiatry 72: 449-454.

Burrell JR, Hornberger M, Carpenter RHS, Kiernan MC, Hodges JR (2012) Saccadic abnormalities in frontotemporal dementia. Neurology 78: 1816-1823

Cameron IGM, Pari G, Alahyane N, Brien DC, Coe BC, Stroman PW, Munoz DP (2012) Impaired executive function signals in motor brain regions in Parkinson's disease. Neuroimage 60: 1156-1170.

Cameron IGM, Watanabe M, Pari G, Munoz DP (2010) Executive impairment in Parkinson's disease: response automaticity and task switching. Neuropsychologia 48: 1948-1957.

Carvalho N, Noiret N, Vandel P, Monnin J, Chopard G, Laurent E (2014) Saccadic eye movements in depressed elderly patients. PLoS ONE 9: e105355

Chamberlain SR, Blackwell AD, Fineberg NA, Robbins TW, Sahakian BJ (2005) The neuropsychology of obsessive compulsive disorder: the importance of failures in cognitive and behavioural inhibition as candidate endophenotypic markers. Neurosci Biobehav Rev 29: 399-419

Chan F, Armstrong IT, Pari G, Riopelle RJ, Munoz DP (2005) Deficits in saccadic eye-movement control in Parkinson's disease. Neuropsychologia 43: 784-796

Clough M, Millist L, Lizak N, Beh S, Frohman TC, Frohman EM, White OB, Fielding J (2015) Ocular motor measures of cognitive dysfunction in multiple sclerosis I: inhibitory control. J. Neurol. 262: 1130-1137.

Coe BC, Munoz DP (2017) Mechanisms of saccade suppression revealed in the antisaccade task. Philos Trans R Soc Lond B Biol Sci. 372(1718): pii: 20160192. doi: 10.1098/rstb.2016.0192

Curtis CE, Calkins ME, Iacono WG (2001a) Saccadic disinhibition in schizophrenia patients and their first-degree biological relatives: a parametric study of the effects of increasing inhibitory load. Exp Brain Res 137: 228-236.

Curtis CE, Calkins ME, Grove WM, Feil KJ, Iacono WG (2001b) Saccadic disinhibition in patients with acute and remitted schizophrenia and their first-degree biological relatives. American Journal of Psychiatry 158: 100-106.

Cutsuridis V (2010) Neural accumulator models of decision making in eye movements. Adv Exp Med Biol 657: 61-72

Cutsuridis V (2015) Neural competition via lateral inhibition between decision processes and not a STOP signal accounts for the antisaccade performance in healthy and schizophrenia subjects. Front. Neurosci. 9:5. doi: 10.3389/fnins.2015.00005.

Cutsuridis V (2017b) A Neural accumulator model of antisaccade performance of healthy controls and obsessive-compulsive disorder patients. In M. K. vanVugt, A. P. 
Banks, \& W. G. Kennedy (Eds.), Proceedings of the $15^{\text {th }}$ International Conference on Cognitive Modeling (pp. 85-90). Coventry, United Kingdom: University of Warwick.

Cutsuridis V (2017a) Behavioral and computational varieties of response inhibition in eye movements. Philos Trans R Soc Lond B Biol Sci, 372(1718). pii: 20160196. doi: 10.1098/rstb.2016.0196.

Cutsuridis V, Kahramanoglou I, Smyrnis N, Evdokimidis I, Perantonis S (2007b) A neural variable integrator model of decision making in an antisaccade task.

Neurocomputing 70(7-9): 1390-1402.

Cutsuridis V, Kumari V, Ettinger, U (2014) Antisaccade performance in schizophrenia: A neural model of decision making in the superior colliculus. Front. Neurosci. 8:13. doi: 10.3389/fnins.2014.00013

Cutsuridis V, Smyrnis N, Evdokimidis I, Perantonis S (2007a) A neural network model of decision making in an antisaccade task by the superior colliculus. Neural Networks 20(6): 690-704.

Damilou A, Apostolakis S, Thrapsanioti E, Theleritis C, Smyrnis N (2016) Shared and distinct oculomotor function deficits in schizophrenia and obsessive compulsive disorder. Psychophysiology 53(6): 796-805. doi: 10.1111/psyp.12630

Depatie L, O'Driscoll GA, Holahan AL, Atkinson V, Thavundayll JX, Kin NNY, Lai $S$ (2002) Nicotine and behavioral markers of risk for schizophrenia: a double-blind, placebo-controlled, cross-over study. Neuropsychopharmacology 27: 1056-1070.

deWilde OM, Dingemans P, Boeree T, Linszen D (2008) Antisaccade deficit is present in young first-episode patients with schizophrenia but not in their healthy young siblings. Psychological Medicine 38: 871-875

Dursun SM, Wright N, Reveley MA (1999) Effects of amphetamine on saccadic eye movements in man: possible relevance to schizophrenia? J Psychopharmacol. 13(3): 245-7.

Evdokimidis I, Smyrnis N, Constantinidis TS, Stefanis NC, Avramopoulos D, Paximadis C, et al (2002) The antisaccade task in a sample of 2006 young men I. Normal population characteristics. Experimental Brain Research 147: 45-52

Everling S, Dorris MC, Klein RM, Munoz DP (1999) Role of primate superior colliculus in preparation and execution of antisaccades and prosaccades. J Neurosci 19: $2740-2754$

Everling S, Fischer B (1998) The antisaccade: a review of basic research and clinical studies. Neuropsychologia 36: 885-899

Everling S, Munoz DP (2000) Neuronal correlates for preparatory set associated with prosaccades and antisaccades in the primate frontal eye fields. J Neurosci 20: 387-400 
Ettinger U, Kumari V, Crawford TJ, Davis RE, Sharma T, Corr PJ (2003) Reliability of smooth pursuit, fixation, and saccadic eye movements. Psychophysiology 40: 620628

Ettinger U, Kumari V, Chitnis XA, Corr PJ, Crawford TJ, Fannon DG, O'Ceallaigh SO, Sumich AL, Doku VC, Sharma T (2004) Volumetric neural correlates of antisaccade eye movements in first-episode psychosis. American Journal of Psychiatry 161: 1918-1921

Fischer B, Weber H (1992) Characteristics of antisaccades in man. Exp Brain Res 89(2): 415-424

Fukushima J, Fukushima K, Chiba T, Tanaka S, Yamashita I, Kato M (1988) Disturbances of voluntary control of saccadic eye movements in schizophrenic patients. Biol. Psychiatry 23: 670-677

Funahashi S, Chafee MV, Goldman-Rakic PS (1993) Prefrontal neuronal activity in rhesus monkeys performing a delayed antisaccade task. Nature 395: 753-756

Gottlieb J, Goldberg ME (1999) Activity of neurons in the lateral intraparietal area of the monkey during an antisaccade task. Nat Neurosci 2(10): 906-912.

Green JF, King DJ (1998) The effects of chlorpromazine and lorazepam on abnormal antisaccade and no-saccade distractibility. Biol Psychiatry 44(8): 709-15.

Green JF, King DJ, Trimble KM (2000) Antisaccade and smooth pursuit eye movements in healthy subjects receiving sertraline and lorazepam. J Psychopharmacol. 14(1): 30-6.

Green CR, Munoz DP, Nikkel SM, Reynolds JN (2007) Deficits in eye movement control in children with fetal alcohol spectrum disorders. Alcohol Clin. Exp. Res. 31: $500-511$.

Grootens KP, van Luijtelaar G, Buitelaar JK, van der Laan A, Hummelen JW, Verkes RJ (2008) Inhibition errors in borderline personality disorder with psychotic-like symptoms. Progress in Neuropsychopharmacology and Biological Psychiatry 32: 267-273.

Guitton D, Buchtel HA, Douglas RM (1985) Frontal lobe lesions in man cause difficulties in suppressing reflexive glances and in generating goal-directed saccades. Exp. Brain Res. 58: 455-472

Hakvoort Schwerdtfeger RM, Alahyane N, Brien DC, Coe BC, Stroman PW, Munoz DP (2013) Preparatory neural networks are impaired in adults with attention-deficit/hyperactivity disorder during the antisaccade task. NeuroImage Clin. 2: 63-78.

Heuer HW, Mirsky JB, Kong EL, Dickerson BC, Miller BL, Kramer JH, Boxer AL (2013) Antisaccade task reflects cortical involvement in mild cognitive impairment. Neurology 81: 1235-1243. 
Hutton SB (2002) Improved antisaccade performance in schizophrenia with risperidone. Commentary. Journal of Neurology, Neurosurgery, and Psychiatry 72: 429.

Hutton SB, Ettinger U (2006) The antisaccade task as a research tool in psychopathology: A critical review. Psychophysiology 43: 302-313

Hutton SB, Joyce EM, Barnes TR, Kennard C (2002) Saccadic distractibility in first episode schizophrenia. Neuropsychologia 40: 1729-1736.

Hutton SB, Crawford TJ, Puri BK, Duncan L-J, Chapman M, Kennard C, Barnes TRE, Joyce EM (1998) Smooth pursuit and saccadic abnormalities in first-episode schizophrenia. Psychological Medicine 28: 685-692

Jahanshahi M, Rothwell JC (2017) Inhibitory dysfunction contributes to some of the motor and non-motor symptoms of movement disorders and psychiatric disorders. Phil. Trans. R. Soc. B 372: 20160198.

Kang SS, Dionisio DP, Sponheim SR (2011) Abnormal mechanisms of antisaccade generation in schizophrenia patients and unaffected biological relatives of schizophrenia patients. Psychophysiology 48(3): 350-61

Karoumi B, Ventre-Dominey J, Vighetto A, Dalery J, d'Amato T (1998) Saccadic eye movements in schizophrenia patients. Psych Res. 77: 9-19

Kaufman LD, Pratt J, Levine B, Black SE (2012) Executive deficits detected in mild Alzheimer's disease using the antisaccade task. Brain Behav. 2: 15-21

Kirenskaya AV, Kamenskov MY, Myamlin VV, Novototsky-Vlasov VY, Tkachenko AA (2013) The antisaccade task performance deficit and specific CNV abnormalities in patients with stereotyped paraphilia and schizophrenia. J Forensic Sci. 58(5): 121926

Klein C, Foerster F (2001) Development of prosaccade and antisaccade task performance in participants aged 6 to 26 years. Psychophysiology 38(2): 179-89.

Kloft L, Kischkel E, Kathmann N, Reuter B (2011) Evidence for a deficit in volitional action generation in patients with obsessive compulsive disorder. Psychophysiology 48: 755-761. doi: 10.1111/j.1469-8986.2010.01138.x

Larrison-Faucher AL, Matorin AA, Sereno AB (2004) Nicotine reduces antisaccade errors in task impaired schizophrenic subjects. Progress in Neuropsychopharmacology and Biological Psychiatry 28: 505-516.

Lennertz L, Rampacher F, Vogeley A, Schulze-Rauschenbach S, Pukrop R, Ruhrmann S, ..., Wagner M (2012) Antisaccade performance in patients with obsessive-compulsive disorder and unaffected relatives: Further evidence for impaired response inhibition as a candidate endophenotype. European Archives of Psychiatry and Clinical Neuroscience 262: 625-634. doi: 10.1007/s00406-012-0311-1 
Levy DL, Mendell NR, Holzman PS (2004) The antisaccade task and neuropsychological tests of prefrontal cortical integrity in schizophrenia: empirical findings and interpretative considerations. World Psychiatry 3: 32-40.

Lo CC, Wang XJ (2016) Conflict resolution as near-threshold decision-making: A spiking neural circuit model with two-stage competition for antisaccadic task. PLoS Comput Biol. 12(8): e1005081. doi: 10.1371/journal.pcbi.1005081

Malsert J, Guyader N, Chauvin A, Polosan M, Poulet E, Szekely D, Bougerol T, Marendaz C (2012) Antisaccades as a follow-up tool in major depressive disorder therapies: a pilot study. Psychiatry Res. 200: 1051-1053.

Maruff P, Purcell R, Tyler P, Pantelis C, Currie J (1999) Abnormalities of internally generated saccades in obsessive-compulsive disorder. Psychological Medicine 29: $1377-1385$.

Massen C (2004) Parallel programming of exogenous and endogenous components in the antisaccade task. Q. J. Exp. Pscyhol. A 57: 475-498.

Meeter M, Van der Stigchel S, Theeuwes J (2010) A competitive integration of exogenous and endogenous eye movements. Biol Cybern 102(4): 271-91

Munoz DP, Armstrong IT, Hampton KA, Moore KD (2003) Altered control of visual fixation and saccadic eye movements in attention-deficit hyperactivity disorder. J. Neurophysiol. 90: 503-514.

Munoz DP, Broughton JR, Goldring JE, Armstrong IT (1998) Age-related performance of human subjects on saccadic eye movement tasks. Exp Brain Res. 121(4): 391-400

Munoz DP, Everling S (2004) Look away: The antisaccade task and the voluntary control of eye movement. Nat. Rev. Neurosci. 5: 218-228

Munoz DP, Istvan PJ (1998) Lateral inhibitory interactions in the intermediate layers of the monkey superior colliculus. J Neurophysiol. 79: 1193-1209

Munoz DP, Wurtz R (1995a) Saccade-related activity in monkey superior colliculus. I. Characteristics of burst and buildup cells. J Neurophysiol 73: 2313-33

Munoz DP, Wurtz R (1995b) Saccade related activity in monkey superior colliculus. II. Spread of activity during saccades. J Neurophysiol 73: 2334-48

Noorani I, Carpenter RH (2014) Re-starting a neural race: anti-saccade correction. Eur J Neurosci. 39(1): 159-64

Noorani I, Carpenter RH (2013) Antisaccades as decisions: LATER model predicts latency distributions and error responses. Eur J Neurosci. 37(2): 330-8.

Paolozza A, Titman R, Brien D, Munoz DP, Reynolds JN (2013) Altered accuracy of saccadic eyemovements in children with fetal alcohol spectrum disorder. Alcohol Clin. Exp. Res. 37: 1491-1498. 
Peltsch A, Hoffman A, Armstrong I, Pari G, Munoz DP (2008) Saccadic impairments in Huntington's disease. Exp. Brain Res. 186: 457-469.

Peltsch A, Hemraj A, Garcia A, Munoz DP (2014) Saccade deficits in amnestic mild cognitive impairment resemble mild Alzheimer's disease. Eur. J. Neurosci. 39: 20002013.

Peltsch A, Hemraj A, Garcia A, Munoz DP (2011) Age-related trends in saccade characteristics among the elderly. Neurobiol Aging. 32(4): 669-79.

Petrovsky N, Ettinger U, Quednow BB, Landsberg MW, Drees J, Lennertz L, Frommann I, Heilmann K, Sträter B, Kessler H, Dahmen N, Mössner R, Maier W, Wagner M (2013) Nicotine enhances antisaccade performance in schizophrenia patients and healthy controls. Int J Neuropsychopharmacol. 16(7): 1473-81

Petrovsky N, Ettinger U, Quednow BB, Walter H, Schnell K, Kessler H, Mössner R, Maier W, Wagner M (2012) Nicotine differentially modulates antisaccade performance in healthy male non-smoking volunteers stratified for low and high accuracy. Psychopharmacology (Berl) 221(1): 27-38

Phillips JM, Johnston K, Everling S (2010) Effects of anterior cingulate microstimulation on pro- and antisaccades in nonhuman primates. J Cogn Neurosci 23(2): 481-490.

Pierrot-Deseilligny CH, Ploner CJ, Muri RM, Gaymard B, Rivaud-Pechoux S (2002) Effects of cortical lesions on saccadic: eye movements in humans. Ann N Y Acad Sci. 956: 216-29.

Radant AD, Dobie DJ, Calkins ME, Olincy A, Braff DL, Cadenhead KS, Freedman R, Green MF, Greenwood TA, Gur RE, Gur RC, Light GA, Meichle SP, Millard SP, Mintz J, Nuechterlein KH, Schork NJ, Seidman LJ, Siever LJ, Silverman JM, Stone WS, Swerdlow NR, Tsuang MT, Turetsky BI, Tsuang DW (2010) Antisaccade performance in schizophrenia patients, their first-degree biological relatives, and community comparison subjects: data from the COGS study. Psychophysiology 47(5): $846-56$

Rycroft N, Hutton SB, Clowry O, Groomsbridge C, Sierakowski A, Rusted JM (2007) Non-cholinergic modulation of antisaccade performance: a modafinil-nicotine comparison. Psychopharmacology 195: 245-253

Schlag-Rey M, Amador N, Sanchez H, Schlag J (1997) Antisaccade performance predicted by neuronal activity in the supplementary eye field. Nature 390: 398-401

Smyrnis N, Evdokimidis I, Stefanis NC, Constantinidis TS, Avramopoulos D, Theleritis C, et al. (2002) The antisaccade task in a sample of 2006 young men. II. Effects of task parameters. Exp. Brain Res. 147: 53-63

Soncin S, Brien DC,Coe BC, Marin A,Munoz DP (2016) Contrasting emotion processing and executive functioning in attention-deficit/hyperactivity disorder and bipolar disorder. Behav. Neurosci. 130: 531-543. 
Tatler BW, Hutton SB (2007) Trial-by-trial effects in the antisaccade task. Exp Brain Res 179: 387-96

Theleritis C, Evdokimidis I, Smyrnis N (2014) Variability in the decision process leading to saccades: A specific marker for schizophrenia? Psychophysiology 51: 327 336. doi: 10.1111/psyp.12178

Tien AY, Pearlson GD, Machlin SR, Bylsma FW, Hoehn-Saric R (1992) Oculomotor performance in obsessive-compulsive disorder. American Journal of Psychiatry 149: $641-646$

Trappenberg TP, Dorris MC, Munoz DP, Klein RM (2001) A model of saccade initiation based on the competitive integration of exogenous and endogenous signals in the superior colliculus. J Cogn Neurosci. 13(2): 256-71.

van der Wee N J, Hardeman HH, Ramsey NF, Raemaekers M, Van Megen HJ, Denys DA,..., Kahn RS (2006) Saccadic abnormalities in psychotropic-naive obsessivecompulsive disorder without co-morbidity. Psychological Medicine 36: 1321-1326. doi: $10.1017 / \mathrm{s} 0033291706007926$

Wiecki TV, Antoniades CA, Stevenson A, Kennard C, Borowsky B, Owen G, Leavitt B, Roos R, Durr A, Tabrizi SJ, Frank MJ (2016)_A Computational Cognitive Biomarker for Early-Stage Huntington's Disease. PLoS One 11(2): e0148409. doi: 10.1371/journal.pone.0148409

Witiuk K, Fernandez-Ruiz J, McKee R, Alahyane N, Coe BC, Melanson M, Munoz DP (2014) Cognitive deterioration and functional compensation in ALS measured with fMRI using an inhibitory task. J. Neurosci. 34: 14260-14271

Zanelli J, MacCabe J, Toulopoulou T, Walshe M, McDonald C, Murray R (2009) Neuropsychological correlates of eye movement abnormalities in schizophrenic patients and their unaffected relatives. Psychiatry Res. 168(3): 193-7

Zanelli J, Simon H, Rabe-Hesketh S, Walshe M, McDonald C, Murray RM, MacCabe JH (2005) Eye tracking in schizophrenia: does the antisaccade task measure anything that the smooth pursuit task does not? Psychiatry Res. 136: 181-188. 


\section{Further Reading}

\section{Scholarpedia}

Human saccadic eye movements

(http://www.scholarpedia.org/article/Human_saccadic_eye_movements)

Frontal eye fields (http://www.scholarpedia.org/article/Frontal_eye_field)

\section{Wikipedia}

Antisaccade task (https://en.wikipedia.org/wiki/Antisaccade_task)

Two alternative forced choice (https://en.wikipedia.org/wiki/Two-

alternative_forced_choice)

\section{Encyclopedia of Computational Neuroscience}

Katz, L., Yates, J., Huk, A. Accumulation of Evidence in Decision-Making

Miller, P. Decision-Making, Models

Miller, P. Decision-Making, Threshold

Hauser, C., Salinas, E. Perceptual Decision-Making

Bogacz, R. Speed-Accuracy Tradeoff

Salinas, E. Decision-Making: Overview

van Wingerden, M., Kalenscher, T. Decision-Making, Bias

van Wingerden, M., Kalenscher, T. Choice Behavior 

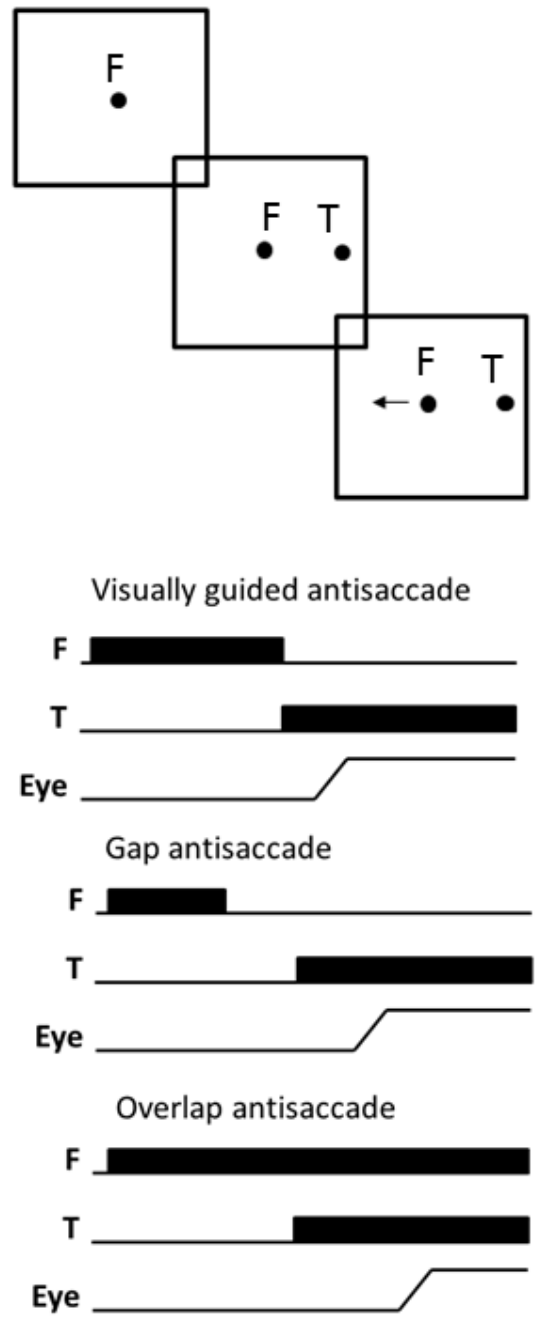

Figure 1. Basic design of the antisaccade task. Typically a participant starts each trial fixating on a stimulus. When a target stimulus appears, the participant must make an eye movement in the opposite direction (antisaccade) of the target stimulus. Visually guided antisaccade: the antisaccade is performed immediately after fixation stimulus (F) is extinguished and target stimulus (T) appears. Gap antisaccade: a gap period exists between disappearance of fixation stimulus and target stimulus appearance. Overlap antisaccade: fixation stimulus remains on during target stimulus presentation. 
A

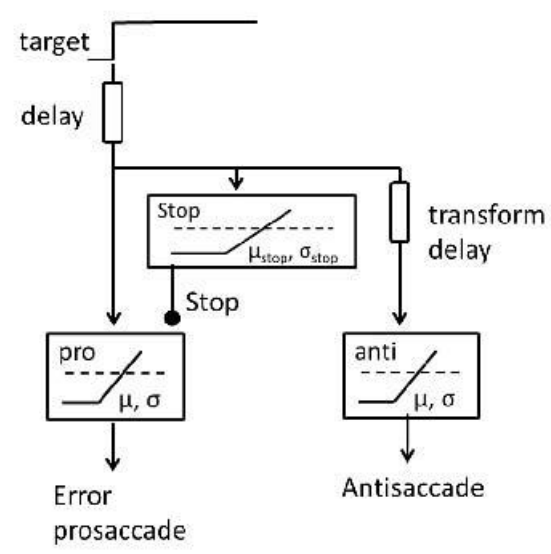

B

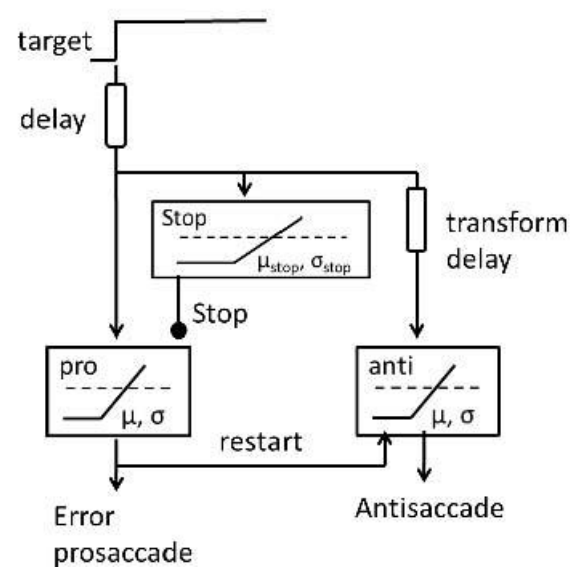

Figure 2. (A) Three-unit antisaccade model. (B) Three-unit antisaccade model with RESTART mechanism. 


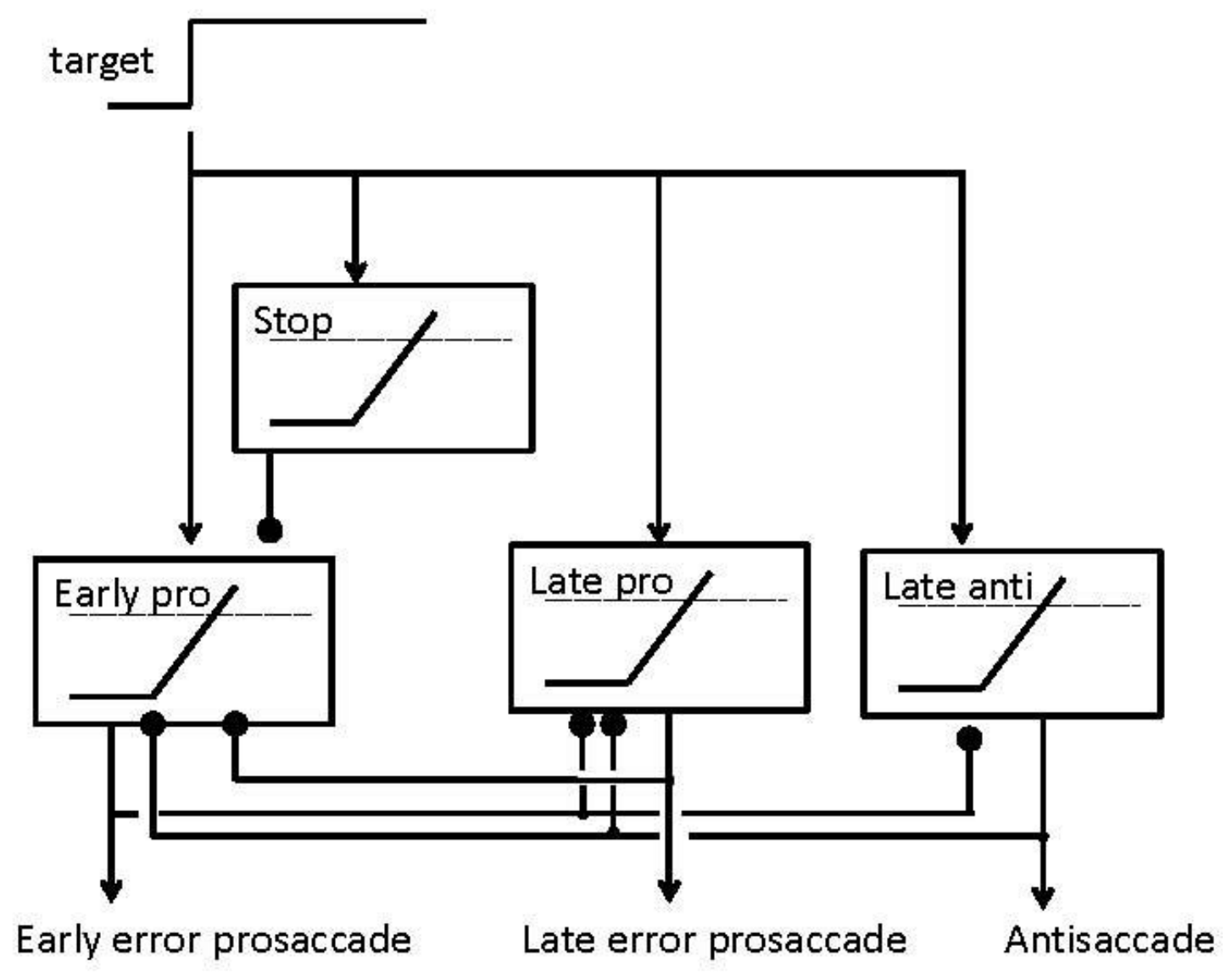

Figure 3. SERIA $\mathrm{A}_{\mathrm{lr}}$ model. The presentation of a visual cue (target) triggers the race of four independent units.. The Stop unit can stop an early response. The late decision process is triggered by the competition between two further units. 
FEF
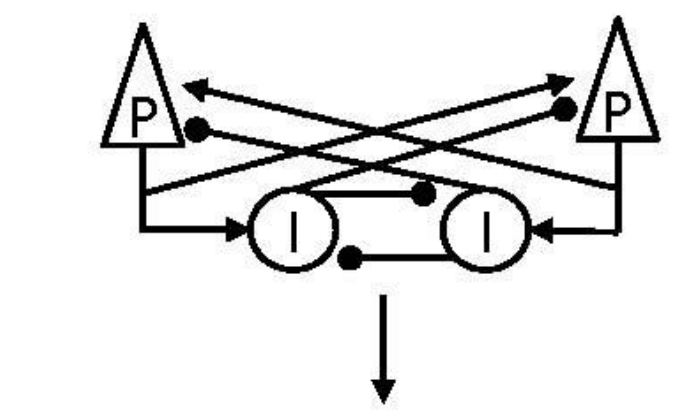
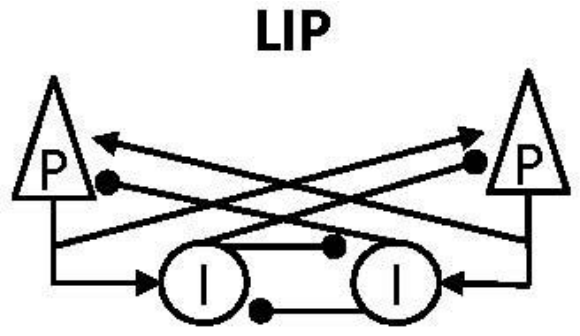

$\downarrow$

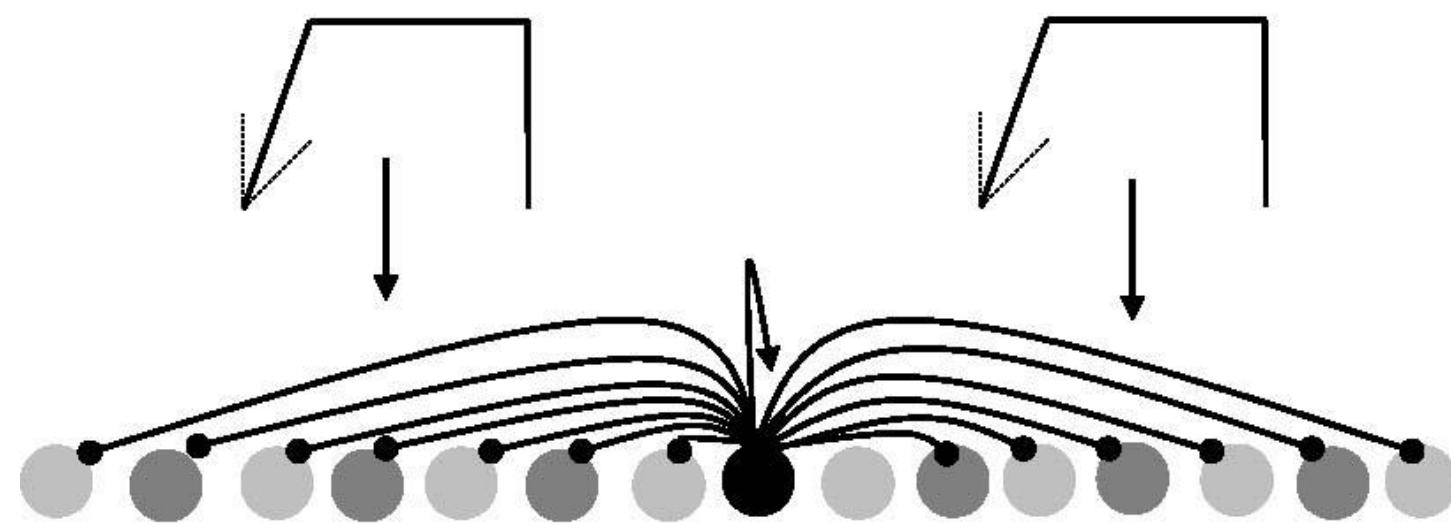

SUPERIOR COLLICULUS

Figure 4. Three module neural accumulator model of antisaccade performance of healthy controls (Cutsuridis et al., 2007a, 2007b). A reactive input (LIP population output) and a planned input (FEF population output) activate the superior colliculus module. Both inputs have a linearly rising phase, whose slope varies from a normal distribution, a plateau phase and an offset phase. Lateral inhibitory interactions between cells mediate the inhibitory effects of inhibitory interneurons in the superior colliculus. P: cortical pyramidal cell; I: cortical inhibitory interneuron; Black node: SC fixation cell; Dark gray node: SC build-up cell; Light gray node: SC burst cell. 


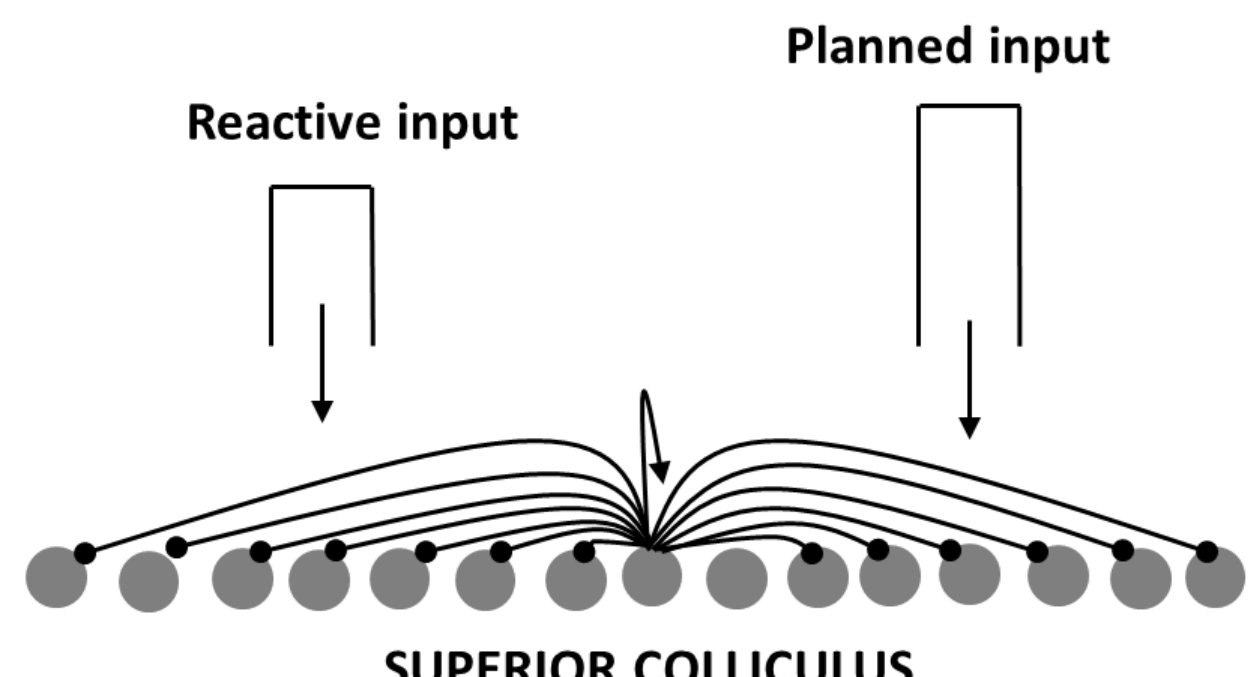

Figure 5. Neural accumulator model of antisaccade performance of schizophrenia and OCD patients (Cutsuridis et al., 2014; Cutsuridis, 2017b). Two inputs activate opposite sides of the superior colliculus: a reactive input originating from LIP, and a planned input originating from FEF. Each node in SC excites itself and inhibits its neighbours (on-centre, off-surround connectivity). Lateral inhibitory interactions between cells mediate the inhibitory effects of inhibitory interneurons in the superior colliculus. Grey node: SC build-up cell. 